\title{
Analysis of Software Requirements for an M-Learning Framework
}

\author{
Sudhindra B. Deshpande \\ Department of Information Science \& Engineering \\ KLS, Gogte Institute of Technology \\ Belagavi
}

\begin{abstract}
In this paper, we propose a software framework for an $\mathrm{m}$ learning environment. Here, we attempt the software requirement analysis for a software tool to be developed for $\mathrm{m}$-learning. As the definition goes ' $\mathrm{m}$-learning is learning while move'. Our aim is to use android supportive smart devices on which this m-learning software will execute.

Developing software for m-learning application is a complex process which requires judicious handling of prioritization, specification, delivering and finally application development. In this paper we try to establish four major and vital requirements such as human-smart device interaction, infrastructure of mobile-computing, packaging and presenting of the learning content, instructional and learning design. Much m-learning software may fail to meet the objective because of non appropriate handling of above mentioned requirements. These requirements are mutually supporting and affecting each other. For example, limited screen size and Internet connectivity limit the size of learning content and user interface. Hence these kinds of requirements are very important to consider during software development of $\mathrm{m}$ learning. Our framework would constitute of smart mobile devices, interacting with cloud using mobile software agents. We are proposing the use of mobile agents for communication between smart devices and cloud.
\end{abstract}

\section{Keywords}

M-learning, mobile agents, jade, android, smart devices, Cloud, e-learning

\section{INTRODUCTION}

Software development for m-learning application is a complex task as it requires integration of software and learning content. And is different compared to other application developments. So this kind of application will include design, develop and delivery of learning contents along with the study of limitations of mobile devices and internet connectivity.

M-learning can be defined as "learning that may take place in multiple locations, across multiple times and addressing multiple content areas using static or portable equipments such as wireless laptops, smart phones or personal media players "[1]. More attention is required towards software engineering practices in developing m-learning software framework; such as requirement elicitation, analysis, optimization of resources. Capturing correct set of requirements in m-learning is challenging task. Missing such requirements reduces the usage of application.

The factors that affect m-learning are- varying devices, various platforms, learning and instructional design [2].

Our aim is to use mobile agent technology in developing this application. Agents can communicate between cloud - the

\author{
Srinivas R. Mangalwede \\ Department of Computer Science \& Engineering \\ KLS, Gogte Institute of Technology \\ Belagavi
}

content storage; and the android devices with user interface. We could provide the learners with the right content at the right time in a personalized environment.

\section{UNDERSTANDING THE REQUIREMENTS}

In this section we analyze and attempt to understand the four major vital requirements such as mobile-computing infrastructure, interaction between human and smart device, packaging and presenting of the learning content, instructional and learning design. The Fig.1 depicts the cooperative environment of these vital requirements.

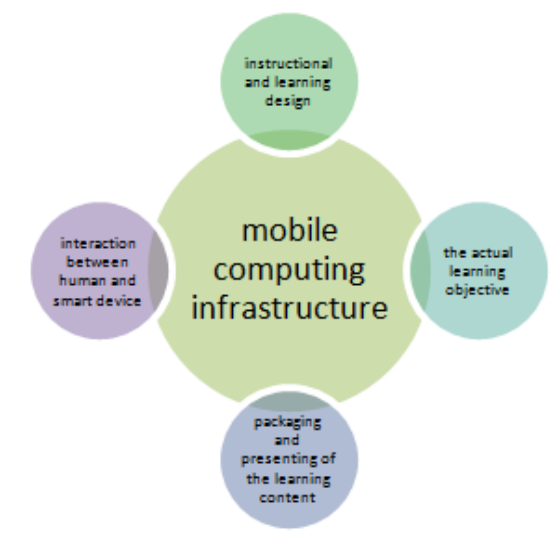

Fig 1: Components of m-learning framework

\subsection{Interaction between human and smart device}

Interaction between human and smart device is nothing but the usage of mobile devices by the users under various circumstances. The usability issues of mobile devices in terms of screen resolutions, size, limitation keyboard, internet connectivity, battery life, directly affects the use this $\mathrm{m}$ learning framework.

Such software could be developed so that it is easy to use, easy to adapt through continuous involvement of mobile users in the design and development process.

\subsection{Mobile environment}

Mobile devices, in particular Android smart phones are seen everywhere now. Android is the first open source and free platform for cell phones. The Open Handset Alliance - group of more than 40 different organizations including ASUS, Google, and HTC ect. have come together to enhance and support the advancements in cell phones. These smart cell phones support multimedia features strongly. Popularity of Android is increasing in application developments. Now a day, Android smart phones coming with various advanced and enhanced features such as HD quality multimedia, good 
processor speed, long life battery, long screen size, Wi-Fi connectivity. Particularly the wireless technology Wi-Fi Direct [3] provides support to the users to make use ad hoc network with other smart devices everywhere and all the time [4].

\subsubsection{Mobile Context}

As the smart devices have become portable mobile context also has changed over the time. One of the major causes for this is the touch sensitive display; which has facilitated the phone app on the smart phones. For learning on smart devices, haptic user interfaces are found to be more suitable than proxy interfaces because the system react to touch the body part i.e. direct sesnomotoric coordination. Interaction with the mobile content through touch is direct; doesn't need any mental translation [5] [6].

\subsubsection{Touch Screen}

For m-learning software touch screen is an important aspect as it is the haptic interface of the smart devices. Mobile ideology has been changing significantly since 2004 . Today user behavior perspective is completely focused on haptic displays; these displays are touché sensitive. Shneiderman's fundamental rules [7] provide the basic guidelines for effective human and computer interaction.

Our m-learning software/application should showcase following characteristics in table 1 for the haptic user interfaces:

Table 1: characteristics of haptic user interface

\begin{tabular}{|l|l|}
\hline Characteristics & Description \\
\hline Ergonomics & $\begin{array}{l}\text { Application should be to user friendly and } \\
\text { should enable the user to learn the } \\
\text { interface quickly. }\end{array}$ \\
\hline Consistency & $\begin{array}{l}\text { Simple and clear navigation on all levels, } \\
\text { in the application need to be available.. }\end{array}$ \\
\hline Relevance & $\begin{array}{l}\text { Exact and user relevant learning material } \\
\text { and information should be presented. }\end{array}$ \\
\hline Scalability & $\begin{array}{l}\text { Learning topics and contents need to be } \\
\text { designed in such a way that frequent } \\
\text { scrolling is prevented. }\end{array}$ \\
\hline Minimalistic & $\begin{array}{l}\text { User should get easy control over the } \\
\text { learning process. }\end{array}$ \\
\hline Portable & $\begin{array}{l}\text { Learning content should be minimal in } \\
\text { volume and should be presented with the } \\
\text { help of video, audio, images, graphics and } \\
\text { animations. }\end{array}$ \\
\hline & $\begin{array}{l}\text { Application should run on any smart } \\
\text { device regardless of what hardware it has. }\end{array}$ \\
\hline
\end{tabular}

\subsection{Instructional information and learning material design}

Instructional information and learning material design focuses on design and development of m-learning content in support with user learning styles and learning theories. Some features of the smart device such as screen size, memory, processing power, battery; put the restrictions on the learning content and its presentation. So there is need of appropriate design of $\mathrm{m}$ learning content. Learning content should include use of MCQs [8], icon instead of text. Content should be pedagogically designed [9] so that effective presentation of the content is possible. Designing digital contents requires analyzing cognitive skills of the students and presenting learning content more logically [10].

M-learning application will provide personalized learning depending on the learners' profile; profiles are constructed based on the various factors of students' characteristics and preferences. Presenting the material/content on various mobile devices' screens, which differ in dimensions, is very difficult. So the need is standardize the material/content according the devices' portfolio and representing it effectively with personalized touch.

Standardizing the learning content is one of the requirements that include metadata which defines learning objects. Learning object is dynamically constructed based on the profiles built from personalization process. Instructional information can be presented in granular fashion [11] and micro lecture format [12].

\subsection{Packaging and presenting of the learning content}

A suitable, adaptive content delivery system requires grouping of the similar contents from various sources and present before the students on their mobile devices. There are two major parts of m-learning: the learning content, and presenting software. The lectures, videos, tutorials, practice tests discussion forums etc. are parts on the learning content. The presenting software consists of OS on the mobile device i.e. Android and m-learning software framework. The $\mathrm{m}$ learning framework should be highly dynamic as to adapt to the new updates of the hardware and software of the mobile devices.

The learning content will be stored on cloud storage in different clusters based on its level of complexity. User on his mobile device will access this learning content based on his preferences. So context aware learning content will be packed suitably and presented to the user.

\subsection{Mobile computing infrastructure}

It includes smart mobile devices and communication infrastructure. Communication infrastructure includes accessibility and availability of internet connection. The mlearning application is affected by the various types of smart devices and availability of internet connection.

This m-learning framework will be making use of intelligent mobile agents for communication. The smart devices will access the required learning content from the cloud storage with the help of mobile agents. The same is depicted in the Fig. 2. 


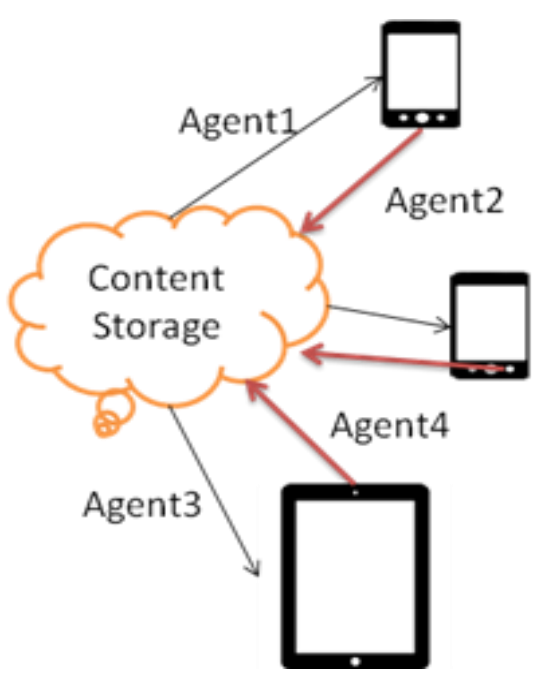

Fig 2: Mobile agents between smart devices and conent storage

\section{PROPOSED MODEL}

The Fig.3 depicts the proposed architecture model for mlearning software framework. The model works in 3 layers.

The Cloud : The learning content will be stored on a cloud database on different clusters. The meterial will be stored in three different formats. Simple text,audio and video. Based on the users' request the content will be delivered.

The Mobile Learning App: which runs on the smart devices requests for some content. It fascilitates the user to register,login and search the interested contents.

The middle layer contains two moodules (i) Mobile Context (ii) Packaging and Presenting.

i. Mobile Context: This module gets all the information about the smart device configuration such as RAM,screen size,battery life,type of smart device etc.

ii. Packaging and Presenting: This module plays very important role. The user requested content will be fetched from cloud and will be packed in a suiatble package according to mobile context . Instructional and content design will be taken care by this module.

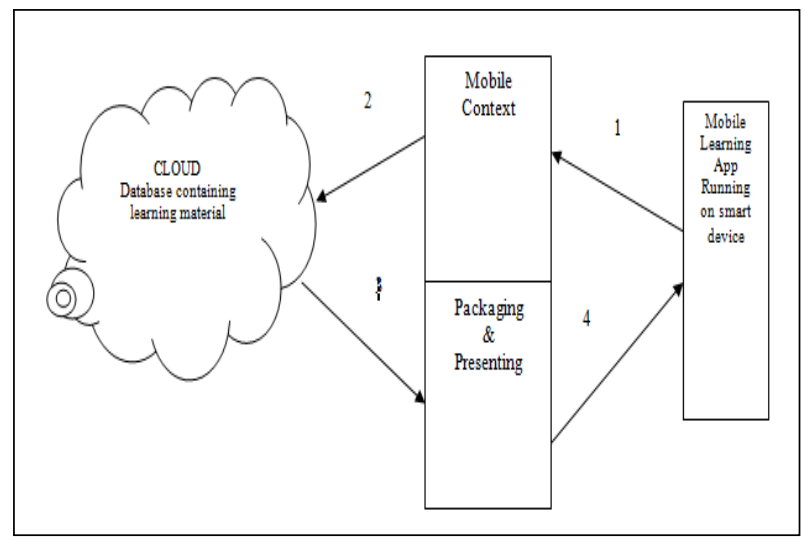

Fig. 3: Framework - 3 layered model

Steps shown in Fig.3.
2. Cloud database is searched for the content

3. Suitable Content is sent back to device

4. Contnent will be packed in a proper format and presented on the device.

To communicate over all the 3 layers, we plan to use mobile agent technology; as it has advantages over the typical clinet server model.

\section{RESULTS AND DISCUSSIONS}

We surveyed 100 users using various portable devices for learning purpose. There were users who prefered smart phones,over other devices such as tablets,laptops and notebooks. The Fig. 4 below depicts the usage of these devices. More than 50\% users use smart phones for the learning purpose.

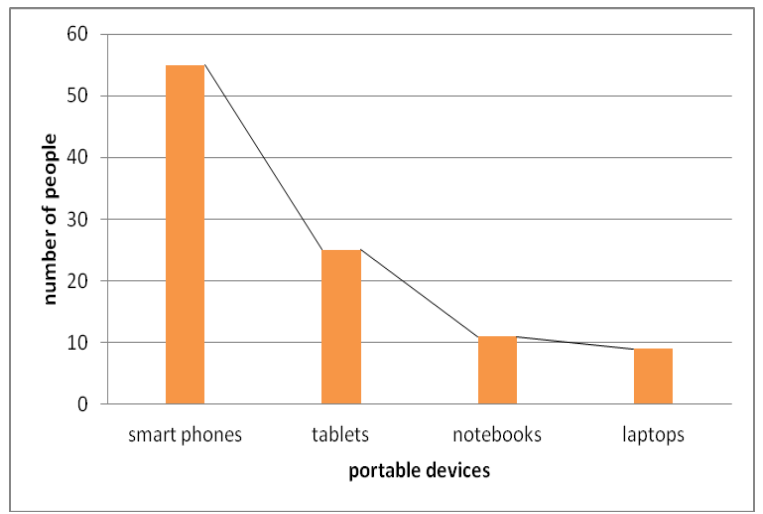

Fig. 4: Number of users using portable devices

Advantages of smart phones and tablets over the notebooks and laptops are as below:

$>$ Quick Start - No need to start/boot the device evry time

$>$ Quick Connect - quick connectivity over the mobile or wifi network

> Easily Movable and carriable - easy to carry and move as the device is small in size

$>$ Focussed Access - access to the content is accurate

$>$ Easy operating system - most devices run on Android

The 3 types of digital contents provided are are in plain text, video and audio files. One more additional file type contains images and pictures. Few user preferences are recorded in table 2 based on their interests and contexts.

Table 2: Content preferences based on user context

\begin{tabular}{|l|l|}
\hline Context & Content type preferred \\
\hline Alone + Silence + Not moving & Plain text \\
\hline Alone + Silence + Moving & Audio \\
\hline Not alone + Moving & Audio + Video + Images \\
\hline Not alone + Noise+ Not moving & Video \\
\hline Alone + Noise + Not Moving & Pictures/Images \\
\hline Alone + Noise + In hurry & Pictures/ Images \\
\hline
\end{tabular}

1. .Learning app requests for content 
The survey result for the above table is depicted below in Fig.5.

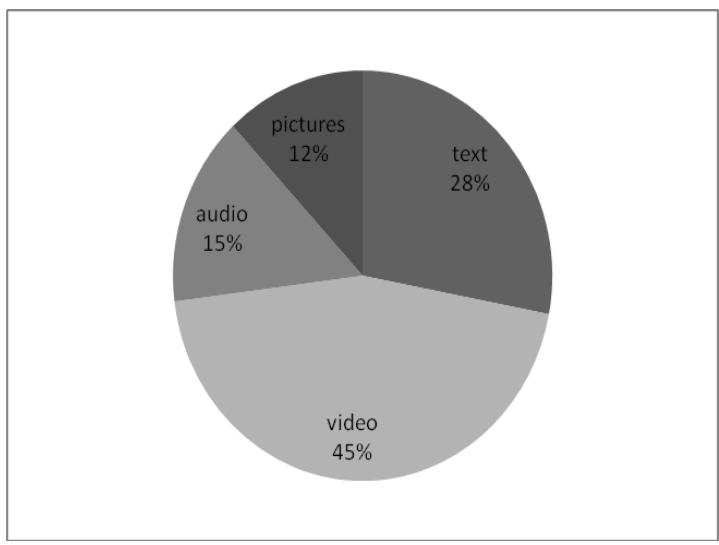

Fig. 5: User preferences for the digital formats

\section{CONCLUSION}

M-learning introduces new kind of teaching - learning, anywhere, anytime. In this paper we have discussed various factors of the requirements that are necessary for an mlearning application. Smart devices, cloud and mobile agents used together to build m-learning application. This framework provides the user with the personalized learning content on the android smart phones. Content delivery and packaging and presenting it to the user are very important aspect. Mobile - computing infrastructure, the backbone of this application. Requirement analyzing for such applications is very challenging and complex for dynamically changing mobile environments in today's world.

\section{REFERENCES}

[1] Sudhindra B.D. and Srinivas .R.M, "Context-Aware Personalized M-Learning Application Using Multi Agents" International Journal of Computer Theory and Applications, ISSN-0974-5572, pp. 459-465, 2017.

[2] M.Sarrab, A.Alzahrani, N.Alalwan and O.Alfarraj, "From traditional learning into mobile learning in education at the university level: under graduate student perspective", International Journal of mobile learning and Organization, vol. 8, pp.167-186, 2014.
[3] A.G.Saavedra, P.Serrano, “ Device-to-Device communications with WiFi Direct: overview and experimentation", IEEE Wireless Communications, vol 20(3) 2013

[4] Mohammed A.,Tanweer A. " Design an M-Learning Framework for Smart Learning in Ad Hoc Network of Android Devices", IEEE International Conference on Computational Intelligence and Computing Research, 2015.

[5] N.Charness, P.Holley, J.Feddon in, T.Jastrzembski, "Light pen use and practice minimize age and hand performance differences in pointing tasks" Human Factros , p. 373 384,2004 .

[6] A.Collins McLaughlin, W.A. Rogers in A.D.Fisk, “ Using Direct and Indirect Input Devices : Attention Demands “ ACM Trans Compute Human Interact, p.1-15, April 2009.

[7] B.Shneiderman, Designing the User Interface : Strategies for Effective Human-Computer -Interaction , Menlo Park : Addison Wesley Longman,1998.

[8] G. Schwabe and C.Goth, "Mobile learning with a mobile gamedesign and motivational effects", Journal of Computer Assisted Learning , vol21, pp. 195-206,2010.

[9] C.Looi, D.Sun and W.Xie, “ Exploring Students' Progression in an Inquiry Science Curriculum Enabled by Mobile learning “, Learning Technologies , IEEE Transactions on vol. 8, pp 43-54,2015.

[10] X.Yang, X.Li and T.Lu " Using mobile phones in collegeclassroom settings : Effects of presentation mode and interest on concentration and achievement" , Computers \&Education, vol.88, pp 292 - 302,2015.

[11] J. Lowenthal , “ Using mobile learning : Determinates impacting behavioural intention",The Amer.Jrnl of Distance Education, vol.24, pp.195-206,2010.

[12] X.Gu, F.Gu and J.Laffey, " Designing a mobile system for lifelong learning on the move", Journal of Computer Assisted Learning, vol.27, pp. 204-215,2011. 